\title{
THE INFLUENCE OF LOGGING ON DOUGLAS FIR BEETLE POPULATIONS ${ }^{1}$
}

\author{
By R. R. LEJEUNE, L. H. McMULLEN, and M. D. ATKINS ${ }^{2}$
}

A brief biography for Mr. Lejeune appeared in Volume 34 (3) on page 299.

L. H. (Les) McMullen received elementary and secondary schooling in Ontario. Following two years in the armed services he attended the Ontario Agricultural College majoring in entomology and graduated in 1950. After one year with the Division of Entomology at Vineland, Ontario, he attended the University of Wisconsin, did graduate work on insect transmission of oak wilt, and received his M.S. in 1952 and his Ph.D. in 1955. Since then he has been studying the Douglas fir beetle with the Forest Entomology and Pathology Branch, Canada Department of Forestry, in British Columbia.

M. D. Atkins was born in England in 1934 and emigrated to Canada in 1940. He attended Victoria College and the University of British Columbia where he received a B.A. degree in 1956 and an M.Sc. degree in 1959, and is now a candidate for a Ph.D. degree at Oregon State University. He joined the staff of the Forest Entomology and Pathology Laboratory at Victoria in 1956 where he has been working on the Douglas fir beetle and insect behaviour.

\section{SUMMARY}

All species of bark beetles of economic importance prefer to attack freshlykilled host material. Logging slash, wind-throw, and fire-killed timber provide ideal breeding grounds for bark beetles. A few species, mostly in the Dendroctonus group, are able to attack and kill living trees. When beetles in this group, raised in preferred host material, cannot find any or enough freshly-killed trees, logs, or slash to enter, they may attack living trees. In the interior of British Columbia, infestations of the Douglas fir beetle can often be traced to logging disturbance.

The regulation or control of bark beetle populations involves several generally accepted principles:

(a) The removal or destruction of beetle broods in infested material in time to prevent the new adult beetles from emerging to attack fresh material.

(b) Continuous logging in time and area will tend to keep the beetles in the slash.

(c) Keep suitable breeding material to a minimum.

(d) The use of trap trees or trap logs for remedial action in trouble areas.

The insects usually associated with logging practices are the bark beetles, ambrosia bettles, and wood borers. Of these only the bark beetles are serious enemies of living trees, and only a few species are aggressive enough to kill trees with any regularity. Even these prefer low vigor trees or those recently killed or weakened by fire, weather, logging, or other biotic agents. Most of the remaining species do not kill living trees unless conditions are such that their numbers increase to huge proportions. When this occurs a

\footnotetext{
${ }^{1}$ Contribution No. 790 Forest Entomology and Pathology Branch, Department of Forestry, Ottawa, Canada.

F Forest Entomology and Pathology Laboratory, Victoria, B.C.
} 
portion of the population may not be able to find suitable breeding sites in slash and other preferred host material and consequently attack healthy trees. The main importance of these bark beetles lies in their ability to weaken healthy trees by top and branch killing, thus creating favorable host material for the more aggressive species, which may ultimately kill the trees.

In British Columbia practically all the species of bark beetles considered capable of killing extensive volumes of living trees belong to the genus Dendroctonus. The most destructive species in British Columbia are the Douglas-fir beetle (D. pseudotsugae Hopkins), a complex known as spruce bark beetles, the mountain pine beetle ( $D$. monticolae Hopkins), and the western pine beetle (D. brevicomis LeConte.) Of these the Douglas-fir beetle is most often responsible for inyestations arising from logging operations.

This paper presents an outline of the inter-relationship between logging and the Douglas-fir beetle and reviews control and preventive measures.

\section{Seasonal Activity}

\section{RESUME OF LIFE HISTORY AND HABITS}

The Douglas-fir beetle overwinters in slash, logs, or trees. Overwintering stages may consist of newly developed adults, larvae of various stages, and old adults that have already made one attack the previous year. During the first few weeks of warm spring weather the overwintered adults emerge and attack new host material. After excavating egg galleries and laying eggs, the old adults die but many of the new adults emerge in the summer to attack again and establish another brood. During the spring and early summer the overwintered larvae develop into new adults, which then emerge and attack along with the re-emerged beetles making a second attack.

The progeny from the spring attack develop into teneral adults by fall and overwinter in this stage. The progeny from the beetles making the summer attack normally overwinter as partially developed and full-grown larvae, but during exceptionally warm summers they may also develop into new adults by fall (Walters, 1956).

\section{Attack Patterns}

A knowledge of how, where, and why bark beetles attack host material is of the utmost importance in developing procedures for control or sanitation. We know that the Douglas-fir beetle, and for that matter most species of bark beetles, prefer recently-killed, including freshly-felled, trees to living trees. We do not yet know what leads beetles to attack a given tree or log, but invariably preferred host material is attacked if there are beetles in the area. Nor do we know how far they will fly to find this material. The Douglas-fir beetle is capable of sustained flights of 20 to 30 miles, but it is believed that they usually do not fly more than a mile or so when there is preferred host material within that radius.

After a few beetles bore into suitable host material a strong secondary attraction is set up which in turn draws many more beetles to the area and, if weather conditions are favourable, what is referred to as a mass attack of the initially infested logs or trees takes place. Attacks may run as high as 24 per square foot but are usually eight to 15 per square foot in 
logs, the attack density usually being higher in living trees than in slash. If the host material which originally brought the beetles to the area becomes "saturated" with attacks, population pressure may cause the beetles unable to find room in it to attack nearby living trees.

This mechanism in their behaviour which induces mass attacks is the main reason why bark beetles are able to kill living trees. In logs or dead trees a light population of beetles can thrive. However, if only a few beetles enter a living tree they are usually quickly drowned out by a flow of pitch. And even with mass attacks, beetles are not always able to kill living trees. Their success in killing trees is probably greater in warm, dry summers, and low vigor trees are more likely to succumb than vigorous trees with a copious pitch flow and rapid growth. It is not unusual for a beetle attack on a living tree to meet with failure, whereas in other instances the attacks are highly successful. A striking illustration of a case where a group of living trees successfully resisted heavy attack occurred in an experimental area near Lac la Hache, B.C., in 1957. In this instance, of 125 trees infested by beetles, only 28 finally succumbed. Therefore if one encounters a patch of trees killed by Douglas-fir beetles, it is possible that a much greater number were attacked and survived.

\section{Attack Density}

Beetles may infest host material in such large numbers that the subsequent development of their larval broods may suffer from starvation and lack of space. Even with attacks of up to 25 per square foot there is no competition for space or food between the beetles themselves when they enter the tree or log, although the parents may abandon galleries earlier in heavily infested than in lightly infested logs. However their developing larval broods need ever increasing space. With heavy attacks the growing larvae eventually have to compete for space and food as they encounter the expanding larval systems of adjacent galleries.

Our studies have shown that there is a trend for fewer beetles to be produced as the attack density increases. The maximum number of progeny are produced per unit area of bark surface when the beetles make between four and seven attacks per square foot. However, population changes are more related to the increase ratio, that is the number of beetles produced in terms of the attacking population. The increase may be 20 -fold when there are only one or two attacks per square foot but this drops markedly as the attack density increases. When the attack density reaches 12 to 13 per square foot, the progeny produced about equals the number of attacking parents, while at still higher attack levels the number of beetles produced may be less than the initial attacking population (McMullen and Atkins, 1961).

\section{Identication of Infested Trees}

For early determination of damage and initiation of control procedures, it is important to detect green-infested trees and treat them before the beetles' progeny leave the following spring. The foliage of a tree killed by the Douglas-fir beetle often does not turn red until the spring following the year of attack. By that time the generation of beetles that developed from the 
attacking population will have left, and possibly will have attacked other living trees.

A green-infested tree can be detected by the reddish brown boring dust that accumulates on the bark, especially around the beetles' entrance holes, and on the ground at the base of the tree. Unlike the bark beetles attacking the pines, no pitch tubes are formed. Therefore in suspect areas the detection of green-infested trees requires that the boles be examined individually. This type of survey can be best accomplished in June.

\section{What Happens In Logged Areas}

This background information can be used to explain how logging can promote the build-up of bark beetle populations. It has been found that the most favourable breeding material for the Douglas-fir beetle consists of freshly-felled logs over eight inches in diameter, and the resulting stumps. Stumps provide from 11 to 35 per cent of the total bark area of residual host material over eight inches in diameter under prevailing logging conditions in the interior of B.C., and they produce more beetles per unit area of bark than other slash types. In some areas certain types of predators are also abundant in stumps. The beetles may attack the tops and logs under eight inches in diameter; but this material dries out so quickly that the larval broods often do not complete development, and the thin bark provides little protection against high temperature in summer or sudden drops in temperature during the fall. Furthermore, parasites are generally more abundant in the thin-barked, small-dimension logs.

Our observations, then, show that the greatest number of beetles are produced in logs over eight inches in diameter and in stumps. The main source of this host material is derived from felled material left in the woods, slash consisting of long butts and cull logs, and right-of-way logs. Freshlyfelled material is the most attractive to the beetles but winter-felled logs also provide suitable sites for beetle reproduction. The importance of slash in producing beetles may be appreciated from recent investigations in the Cariboo region of British Columbia. In several timber sales examined there was enough debris left on the ground to produce, on the average, enough beetles per acre to kill thee large trees. In some, samples the slash was capable of producing enough beetles per acre to kill $\frac{3}{2}$ trees.

Practically every recommendation made for the prevention or control of bark beetle infestations contains a clause that says in effect "logging should be continuous in time and area". By time is meant that logging should continue from year to year at roughly the same rate in a given locality, and by area is meant that logging in any given year should be roughly contiguous to the previous year's logging. Where these practices are followed the beetles coming out of last year's slash go into the nearby current year's slash. If the area and amount of slash is roughly similar to the previous year, the slash should absorb most of the attacking population. Also the beetles will probably attack in densities high enough, i.e. over 13 per square foot, to prevent an increase in the population. Under these conditions there is a more or less stable situation where the risk of infestations developing in living trees is low. 
If, however, either the "time" or "area" factor is ignored in sanitation procedures, the stage is set for infestations to develop in the adjacent stands. If logging is discontinued in an area, the beetles produced in the previous year's slash have no new host material to enter when they emerge. They will then search for suitable host material in the form of blowdown, trees damaged by fire or logging, especially those with roots damaged by road cuts, or trees weakened or dying from natural causes. When this kind of material is found the beetles attack and trigger the strong secondary attraction described earlier, which draws more beetles into the area. The population excess may then attack healthy trees. Thus trees along the margin of a logging operation are particularly susceptible and care should be taken to keep damage of timber in margins to a minimum.

The same result can be expected when new logging slash is laid down at some distance from the previous year's slash. The beetles emerging from the old slash may not find the new slash, and seek out nearby natural, preferred host material, thereby starting new centres of infestation. Although it is known that individual beetles can fly considerable distances, it is believed that mass movements of beetles to areas containing slash is limited to much shorter distances, possibly a mile or less. This is particularly important in years when the temperature is below normal (see Atkins and McMuilen 1960).

\section{Preventing and Controlling Outbreaks}

We are now in a position to consider what can be done to prevent, control, or reduce losses caused by bark beetles. These recommendations fall into three broad categories: I. Preventive Measures, II. Remedial Measures, and III. Methods of Brood Destruction.

\section{Preventive Measures}

These procedures may be divided into two groups: A. Log and Slash Disposal and B. General Logging Practices. These are listed in order of effectiveness in accordance with present knowledge. ,

\section{A. Log and Slash Disposal}

1. All logs should be removed and utilized within one year of time of felling, except that trees felled during May, June, and July should be removed before the following April.

2. All culls and slash over eight inches in diameter should be kept to a minimum and, if infested, treated to prevent emergence of the brood within the time specified above for the removal of logs.

3. Tops should be kept small (under eight inches in diameter). Tree length logging is a good practice wherever feasible.

4. Stumps should be cut as low as possible and, if infested, treated to destroy the bark beetles in them.

5. Roads and right-of-ways should be cut in the fall immediately prior to their use. If logs, slash, etc., resulting from road construction can be utilized or treated as in steps 1 to 4 above, cutting roads and rightof-ways in early spring would remove some of the beetle population. Stands adjacent to new roads should be carefully examined in late summer of the year of road construction and infested trees removed. 
Trees with root damage should be re-examined for attack the summer of the next year. If infested, they should be removed.

6. Procedures 1 to 4 should receive special attention during the last year of logging in an area.

B. General logging practices

1. Priority should be given to overmature or decadent stands, particularly those in which the Douglas-fir beetle is active.

2. Logging should be continuous in time and area. Fresh slash should be laid down in adjacent areas from year to year, and an effort made to prevent large changes in quantity.

3. The residual stand should be carefully watched for evidence of infestation and infested trees removed promptly.

4. Trees felled during May and June will absorb much of the beetle population. If this felling procedure is followed, it must be accompanied by strict sanitation as in Al to 4 .

5. Care must be taken that as little mechanical damage as possible occurs to the residual stand. This includes root damage such as that caused by road cuts.

\section{Remedial Measures}

If, in spite of all precautions, infestations develop in standing timber, remedial action may be necessary for control. The procedures recommended under "I. Preventive Measures" should be continued, and if possible, intensified. These may then be supplemented by a trap tree program. This consists of felling groups of green trees, about 10 per group, shortly prior to beetle flight in the spring. The groups should be placed where they can be easily removed. The trouble area should be gridded with groups of trap trees at about $1 / 4$ to $1 / 2$ mile intervals. Beetles will be attracted to these trap trees and may attack some adjacent green trees as well; all of the resulting infested material should be removed from the area preferably by fall and certainly before April of the following year.

\section{Methods of Brood Destruction}

1. Piling and Burning

The fire should be intense and all bark should be thoroughly burned. Tree-length logging to a central location where cull logs are removed should facilitate this procedure.

2. Peeling.

Peeling the bark exposes the broods to weather and predators. Since many beetles can overwinter in the forest duff, peeling should be done in July or August, before the young adults develop. The procedure increases the fire hazard but when used in conjunction with the burning method, requires a less intense burn.

3. Chemical Spraying

Oil solutions and water emulsions of various fumigants have been used for control of bark beetles and are effective in destroying broods of the Douglas-fir beetle. One of the most commonly used insecticides is ethylene dibromide. The insecticide is applied from tank-type pressure sprayers equipped with a valve by which the rate of application is regulated. 
The nozzle should deliver a fine fan-shaped spray. Since ethylene dibromide freezes at about $49^{\circ} \mathrm{F}$. it should be applied during the summer. Some proprietary products with an ethylene dibromide base contain substances to lower the freezing point of formulation.

SPRAY Formulation

Ethylene dibromide-15 pounds. Emulsifier-21/2 pounds.

Fuel oil to make 4 Imperial gallons.

Add 16 gallons of water to this concentration.

The ethylene dibromide, emulsifier and fuel oil should be thoroughly mixed first. The water is then added and the material thoroughly agitated to make a homogeneous mixture. Formulations should be used as soon as possible after mixing.

Although less disagreeable than other insecticides used to kill bark beetles, ethylene dibromide is sufficiently toxic to warrant considerable care in its use. Pure lanolin should be applied to hands and face, and goggles and rubber gloves should be worn while mixing since ethylene dibromide will blister the skin.

4. Storing recently attacked logs in water prior to milling will kill broods of the beetle in the submerged portions.

\section{REFERENCES}

ATKINS, M. D. and L. H. McMULLEN, 1960. On certain factors influencing Douglas fir beetle populations. Fifth World Forestry Congress, Seattle, U.S.A., 1960.

McMULLEN, L. H. and M. D. ATKINS, 1961. Intraspecific competition as a factor in the control of the Douglas fir beetle, Dendroctontis psendotsugae Hopk. Forest Science. 7: 197-203.

WALTERS, J. 1956. Biology and control of Douglas fir beetle in the interior of British Columbia. Can. Dept. Agric. Publ. 975.

(Continued from page 307 )

of a highly sophisticated attitude to resource use and evaluation. When practising sustained yield, however, we should not become so interested in the far distant future that we fail to satisfy present needs. Our primary responsibility is to encourage and participate in the current development of more efficient ways of harvesting, manufacturing, selling, and growing Canadian forest products.

In our new policy and program we should try to develop a better understanding of the duties, responsibilities, and potential of foresters, especially in industry. Some employers expect too much of recent graduates and count too little on the experience of their older men.

In all of our work we should remember that whether we are managers in government or industry, field foresters, research workers, consultants or educators we are united primarily by our love for forests and the crops they produce. We deserve to call ourselves professional foresters only if we develop and use wisely a modern, vital, ever-growing, highly specialized, yet general body of information about forests and forestry.

Our past record is good. Our present responsibilities are great. In the immediate future we need a policy and program that will encourage us to work together even more effectively through the C.I.F. and help to ensure better forests and forestry for all Canadians.

J. H. G. SMITH 